\title{
O INTERNACIONALISMO COMO PRÁTICA PEDAGÓGICA NA ESCOLA NACIONAL FLORESTAN FERNANDES
}

\author{
EL INTERNACIONALISMO COMO PRÁCTICA PEDAGÓGICA EN LA ESCUELA \\ NACIONAL FLORESTAN FERNANDES
}

\author{
INTERNATIONALISM AS PEDAGOGICAL PRACTICE AT FLORESTAN \\ FERNANDES NATIONAL SCHOOL
}

DOI: https://doi.org/10.9771/gmed.v13i3.47176

Fábio Tomaz Ferreira da Silva ${ }^{1}$

Rosana Cebalho Fernandes ${ }^{2}$

\begin{abstract}
Resumo: No presente texto apresentamos um panorama geral sobre como o Movimento dos Trabalhadores Rurais Sem Terra (MST) compreende e implementa concretamente a questão do internacionalismo entendido como princípio, valor e estratégia desde as ações específicas que desenvolve, mas também em relação a um projeto amplo e profundo da classe trabalhadora do mundo. Nesse sentido, o internacionalismo não é apenas uma ação para fora, senão também para dentro dos territórios que são as bases do Movimento e onde os sujeitos estão inseridos nos processos de lutas e resistências permanentemente. Um desses territórios é a Escola Nacional Florestan Fernandes (ENFF), uma escola de formação política para militantes, dirigentes e quadros das organizações populares da classe trabalhadora nacional e internacional. Na ENFF, desde a concepção de formação do Movimento reafirmamos o internacionalismo como prática pedagógica a partir das dimensões formativas e seus tempos pedagógicos imprimindo no cotidiano a organização rigorosa de um programa, a vivência entre as pessoas durante um determinado período e as sínteses que ajudam a identificar elementos comuns que reafirmam as tarefas dos militantes em seus países e territórios, desde as suas organizações populares e o seu projeto estratégico. Apresentamos também algumas práticas históricas que a ENFF organiza e foi se constituindo em uma referência internacional, como o plantio no bosque da solidariedade, os nomes das turmas, os cursos organizados para o público de outros países para além do Brasil, bem como a presença de militantes permanentes que compõem a Brigada Apolônio de Carvalho (BAC). Reafirmamos que nesse processo a Escola vai elaborando e reelaborando o seu fazer político e pedagógico, aprofundando o seu método e construindo alternativas junto ao desafio de emancipação do ser humano e da sociedade como um todo.
\end{abstract}

Palavras-chave: Internacionalismo. Organização Popular. Escola. Formação. Território.

Resumen: En este texto presentamos un panorama de cómo el Movimiento de los Trabajadores Rurales Sin Tierra (MST) entiende e implementa concretamente el tema del internacionalismo entendido como principio, valor y estrategia desde las acciones específicas que desarrolla, pero también en relación a un proyecto amplio y profundo de la clase trabajadora del mundo. En este sentido, el internacionalismo no es solo una acción hacia al exterior, sino también hacia los territorios que son la base del Movimiento y donde los sujetos se insertan permanentemente en los procesos de lucha y resistencia. Uno de estos territorios es la Escuela Nacional

Florestan Fernandes (ENFF), una escuela de formación política para militantes, dirigentes y cuadros de organizaciones populares de la clase trabajadora nacional e internacional. En la ENFF, desde la concepción de la formación del Movimiento, reafirmamos el internacionalismo como práctica pedagógica desde las dimensiones formativas y sus tiempos pedagógicos, imprimiendo en la vida cotidiana la organización rigurosa de un programa, la experiencia entre las personas durante un período determinado y las síntesis que ayudan a 
Debate

identificar elementos comunes que reafirman las tareas de los militantes en sus países y territorios, desde sus organizaciones populares y su proyecto estratégico. También presentamos algunas prácticas históricas que la ENFF organiza y se ha convertido en un referente internacional, como la plantación en el Bosque Solidario, los nombres de las clases, los cursos organizados para audiencias de países distintos a Brasil, así como la presencia de militantes que integran la Brigada Apolônio de Carvalho (BAC). Reafirmamos que en este proceso, la Escuela está desarrollando y re elaborando su trabajo político y pedagógico, profundizando su método y construyendo alternativas con el desafío de emancipar al ser humano y a la sociedad en su conjunto.

Palabras clave: internacionalismo. organización popular. Escuela. Formación. territorio.

Abstract. In this text we present an overview of how the Landless Rural Workers Movement (MST) understands and concretely implements internationalism as a principle, value and strategy from the specific actions it develops, but also in relation to a broad project of working class in the world. In this sense, internationalism is not just an action towards the outside, but also towards the territories that are the bases of the Movement and where the subjects are permanently inserted in the processes of struggle and resistance. One of these territories is the Florestan Fernandes National School (ENFF), a school for political education for activists, leaders and cadres of popular organizations of both national and international working class. At ENFF, from the conception of political education of MST, we reaffirm internationalism as a pedagogical practice from the formative dimensions and its pedagogical times, imprinting in the daily life the rigorous organization of a program, the experience among people during a certain period and the syntheses that help to identify common elements that reaffirm the tasks of activists in their countries and territories, from their popular organizations and their own strategic project. We also present some historical practices that the ENFF organizes and has become international reference, such as the planting in the Solidarity Forest, the names of the classes, the courses organized for audiences from countries others than Brazil, as well as the presence of permanent activists that make up the Apolonnio de Carvalho Brigade (BAC). We reaffirm that in this process, the School is developing and re-elaborating its political and pedagogical work, deepening its method and building alternatives with the challenge of emancipating human beings and society as a whole.

Keywords: Internationalism. Popular Organization. School. Political Education. Territory.

\section{Introdução}

A Escola Nacional Florestan Fernandes e o seu internacionalismo nasce e se configura como um dos territórios do Movimento dos Trabalhadores Rurais Sem Terra (MST) onde se materializam a sua concepção de ações internacionalistas. Evidentemente, buscamos compreender os seus pressupostos conceituais junto à trajetória política e organizativa que tanto o MST quanto a ENFF desenvolvem historicamente, do ponto de vista de um movimento popular camponês de massas e de uma Escola que se consolida como uma referência mundial desde os seus processos formativos, através do seu método pedagógico.

Ressaltamos que a prática internacionalista do MST estão para além das viagens dos seus dirigentes para outros países, mas que as viagens fazem parte do processo formativo e de articulação com outras organizações e povos. Destacamos que a presença dos Sem Terra em outros lugares do mundo possibilita fortalecer as relações populares, conhecer mais de perto a conjuntura nacional, compreender as forças políticas que configuram projetos estratégicos da classe trabalhadora, bem como reafirmar o valor da humildade, ou seja aprender com as demais organizações.

O referido método perpassa pelas bases do Materialismo Histórico Dialético (MHD), fundamentando-se nas experiências dos clássicos da Pedagogia Socialista, à luz da Educação Popular com base no pensamento de Paulo Freire, desde a Pedagogia do Oprimido, bem como bebendo na fonte da Pedagogia do Movimento como um dos acúmulos da história do próprio MST e das lutas desencadeadas na formação dos sujeitos humanos que dele participam. 
Debate

Neste artigo, queremos refletir e apresentar aos leitores um dos aspectos da prática pedagógica da ENFF que é resultado histórico e dialético do fazer cotidiano que é o seu caráter internacionalista. Esse caráter é resultante da práxis implementada desde as formulações teóricas quanto das práticas concretas desenvolvidas no projeto emancipador de formação do qual a Escola é uma das protagonistas.

Podemos afirmar que a dinâmica na qual a ENFF está envolvida, não apenas do ponto de vista do seu interior, mas das ações do conjunto do MST e da luta de classes como um todo, é uma experiência profunda que vai do universal ao particular e vice versa. Sendo assim, devemos analisá-la tanto na sua forma como no seu conteúdo, ou seja, pensa-la deste o seu jeito organizativo de funcionar quanto nos princípios e valores que prevalece na sua natureza. Dessa maneira, vamos entender o elemento do internacionalismo como um dos conteúdos postos no seu funcionamento.

O Projeto Político Pedagógico (PPP) da ENFF contempla uma série de dimensões vistas como essenciais à suas práticas educativas. Ao longo de seus 16 anos de atividades, a Escola atua a partir do objetivo principal de formar militantes, dirigentes e quadros de organizações populares. Para tal, realiza diversos cursos, seminários, atividades culturais, encontros e reuniões de caráter nacional, continental e internacional. É a partir da sua abrangência mundial que podemos olhar com mais afinco para o papel que cumpre o internacionalismo como um elemento pedagógico nesses processos formativos.

Nesse sentido, no decorrer do presente, faremos dois movimentos de análise, por um lado, conceitualizar e posicionar a compreensão do internacionalismo no marco das concepções e práticas do MST que incidem sobre os processos formativos da Escola. Por outro, discorrer e conceitualizar alguns dos principais componentes da concepção de formação e da prática pedagógica da ENFF. A partir desses elementos, analisar como o internacionalismo cumpre um papel pedagógico na diversidade de atividades desenvolvidas no interior da Escola.

\section{O internacionalismo: a sua concepção e prática no MST}

O longo processo histórico de transformações econômicas, políticas, sociais e culturais que resultaram no desenvolvimento do capitalismo como sistema hegemônico de organização da sociedade também implicou na universalização de determinadas formas de produção e reprodução da vida em sociedade de diferentes partes do mundo.

A consolidação do capitalismo, desde seu polo central de acumulação na Europa ocidental do século XIX, determinou uma nova fase nas relações internacionais que, embora de matriz econômica destacada, refletiu em muitos outros aspectos das diferentes sociedades e nos padrões de suas configurações de classes. Após o longo processo de consolidação do poder político da burguesia desde suas disputas com o sistema monárquico e resquícios feudais europeus, houve um maior 
Debate

impulso, tipicamente capitalista, na imposição de padrões econômicos normatizados pela subsunção do trabalho ao capital.

Este processo ainda que ajustado às realidades particulares e condicionantes endógenas dos países do mundo, reproduz em seu sentido geral a polarização de classes típica do próprio sistema capitalista, ou seja, o conflito de interesses entre uma classe de possuidores de meios de produção e capital por um lado, e por outro os interesses da classe trabalhadora que, despossuída dos elementos constituintes da primeira é forçada a dispor da única mercadoria que possui, a força de trabalho como forma de sobrevivência no marco de uma sociedade que é, sobretudo, uma sociedade de mercadorias.

Assim, a principal consequência de um modo de produção cujo objetivo existencial, a valorização do valor, independe de fronteiras nacionais, é a consolidação de classes sociais sob condições semelhantes. Portanto, não só a formação e a consolidação do sistema capitalista são internacionais, como também o é sua reprodução.

Essa "igualdade" imposta sob condições históricas a diversos povos do mundo passou a ser um componente central da resistência, das lutas e dos projetos políticos da classe trabalhadora internacional. Embora a expressão política mais organizada, no sentido de um projeto político de superação da ordem burguesa, remonte à organização dos trabalhadores industriais europeus do século XIX, as formas nas quais essa universalidade da classe trabalhadora se expressou em diferentes partes do mundo inclui outros processos históricos do desenvolvimento dessas sociedades que antecedem a consolidação plena do sistema capitalista.

Da mesma forma que a transformação da Liga dos Justos em Liga dos Comunistas e o seu famoso Manifesto significou um marco na afirmação do caráter de classe das reivindicações históricas da classe trabalhadora europeia, e com isso impôs-lhe maior radicalidade, a classe como componente de identificação comum, em outras partes do mundo, se conectou com processos históricos particulares das formações sociais locais. $\mathrm{Na}$ América Latina e, consequentemente no Brasil, essa compreensão da universalidade da categoria classe trazida pelo capitalismo estabelece um diálogo com as formas de explorações anteriores marcadas, essencialmente, pelo processo colonial.

Embora os processos coloniais sejam parte constituinte da gênese e desenvolvimento do modo de produção capitalista, a resistência e as lutas organizadas desde os setores explorados e marginalizados dessas sociedades assumiram um novo patamar, sendo mais político por assim dizer, na medida em que ideias da crítica à economia política convocam a um projeto mais amplo de superação da ordem estabelecida para além do imediato, do corporativo e particular.

Dessa maneira, o internacionalismo de classe no contexto latino americano possui uma dupla dimensão inteiramente complementar. Por um lado, expressa como o ordenamento hegemônico do capital submete populações inteiras a uma realidade determinada por lógicas semelhantes de exploração. Não apenas o sistema capitalista é mundial, mas no contexto dos países periféricos e dependentes, seus mecanismos de espoliação se tornam ainda mais evidentes. Ou seja, 
Debate a universalidade das relações capitalistas se expressa de maneira desigual entre centro e periferia. Embora a identidade da classe trabalhadora contenha elementos comuns em ambos os polos, esses elementos também se manifestam de forma diferenciada entre a classe trabalhadora do centro e da periferia do capital.

Por outro lado, entretanto, o internacionalismo de classe na América Latina implica em pensar com profundidade a própria composição da classe trabalhadora nesses territórios, cujos traços coloniais marcados por transversalidades étnicos raciais impactam em sua composição atual. Além disso, o caráter de classe igualmente implica em uma compreensão mais elaborada das lutas históricas desses setores marginalizados e explorados antes mesmo da imposição plena das dinâmicas de classe "puramente" capitalistas.

Dessa maneira, o internacionalismo de classe trata de um processo que articula o resgate histórico da memória de lutas e da formação social com a construção de um projeto político de superação da ordem hegemônica. Pois da mesma forma que a gênese, desenvolvimento, consolidação e reprodução do sistema capitalista foi e é um processo internacional, também será de ordem internacional a sua superação.

Do ponto de vista histórico dos trabalhadores camponeses e na dinâmica do modo de produção capitalista atuar no campo, a partir da apropriação da terra e territórios com toda a biodiversidade que neles existem, configura-se o agronegócio como um projeto internacional para a agricultura mundial. Sendo assim, busca submeter a classe trabalhadora camponesa aos seus interesses. Porém a luta organizada pelos camponeses é de enfrentamento a esse modelo, transformando as lutas locais, regionais e nacionais em ações e articulações internacionais, pois o inimigo se tornou comum em todos os países.

É desse processo que surge o Movimento dos Trabalhadores Rurais Sem Terra (MST) e a sua concepção de internacionalismo como um movimento popular resultado das dinâmicas da questão agrária no Brasil. Podemos afirmar que a diversidade de sujeitos envolvidos no Movimento apresenta traços de resistências históricas, dos indígenas aos escravos, passando pelos camponeses sem-terra e trabalhadores impactados pelo contínuo processo de proletarização das relações de trabalho no campo.

Além disso, a gênese do MST expressa componentes internacionais, especialmente na América Latina no contexto das lutas internacionalistas contra as ditaduras civis militares. No início do MST, no final da década de 1970 a solidariedade de organizações internacionais e a presença de

seus representantes no primeiro congresso nacional significou a ampliação da luta para um movimento que estava sendo construído com a perspectiva de lutar pela terra, pela reforma agrária e pela transformação da sociedade com fundamentos socialistas.

Ao novo sindicalismo brasileiro da década de 1970 soma-se como condicionantes para a organização dos camponeses Sem Terra a influência da Teologia da Libertação, um fenômeno de 
Debate

caráter latino-americano e as Revoluções Cubanas e Sandinista. Enquanto o novo sindicalismo imprimiu uma dimensão corporativa à luta pela reforma agrária, a Teologia da Libertação, por sua vez, influenciou no método de trabalho de base e no caráter massivo e popular da luta, a partir da necessidade de politização das bases sociais para qualquer processo legítimo de mudança social. Já a Revolução Cubana se constituiu como um horizonte e referência de ordem ético política enquanto que a Revolução Sandinista foi um exemplo de protagonismo popular em mudanças estruturais. Soma-se a tudo isso o contexto das ditaduras civis militares como já mencionado anteriormente cujos impactos foram continentais.

Desta maneira, o MST já nasce com uma dimensão não apenas internacional, mas sobretudo internacionalista. O internacionalismo para o Movimento é concebido desde três dimensões fundamentais que são como princípio, valor e estratégia. A dimensão do internacionalismo como princípio está no sentido de uma dimensão "ético moral" que orienta as condutas e comportamentos dos militantes da organização. A dimensão do valor tal qual um alicerce, é um componente constitutivo da prática da organização na implementação e vivência dos valores humanistas e socialistas. E a dimensão da estratégia é um componente que ao fazer parte da leitura da realidade, também formula sua intervenção na mesma, a partir de objetivos definidos diante de um projeto estratégico.

Sendo assim, a concepção de internacionalismo do MST só existe em relação direta com a prática que engendra, que assume a forma em distintas modalidades que, em seu conjunto, exercitam ativamente as dimensões de princípio, valor e estratégia. Algumas das modalidades da prática internacionalista vivenciada desde o conjunto do Movimento acontecem através da organização de Comitês de Amigos do MST em países com França, Bélgica, Itália, Estados Unidos da América, Canadá, Suécia, País Vasco entre outros. Ressaltamos a importância dos comitês para aglutinar solidariedade política em torno das demandas conjunturais como por exemplo em casos de prisões políticas de lideranças e processos de criminalização ao Movimento. Além disso, para a construção da infra estrutura da ENFF cumpriu um papel importante na organização da exposição de fotos da Coleção Terra na qual integrava o trabalho fotográfico de Sebastião Salgado, o livro prefaciado por José Saramago e o CD de canções de Chico Buarque de Holanda, cujo recursos financeiros arrecadados destinaram-se para a construção, nascendo aí um aspecto do internacionalismo incorporado na Escola, ao mesmo tempo que ampliou-se o reconhecimento do Movimento em todo o mundo.

Destacamos a participação constante do MST na construção e articulações da Via Campesina Internacional fundada em 1993, cujo objetivo principal é coordenar organizações camponesas para ações e mobilizações unitárias em defesa da terra, do território e dos bens comuns da natureza como patrimônios da humanidade. Na América Latina a articulação ocorre através da Coordenadoria Latino Americana de Organizações del Campo (CLOC) "com o objetivo de 
Debate

estabelecer a solidariedade e unidade nas diversidades entre as organizações camponesas" (ITERRA/UFFS, p. 60, 2015).

A partir de 2004, com a efervescência dos governos progressistas no contexto latino americano vai sendo construída a proposta do projeto Aliança Bolivariana para os Povos de Nossa América (ALBA) que na articulação com os movimentos populares foi se constituindo numa articulação desde os mesmos, sendo reconhecida até os dias atuais como ALBA Movimentos. Essas experiências são fortalecidas por compreender a necessidade de ampliar do ponto de vista internacional ações contra o imperialismo, o neoliberalismo e o patriarcalismo como bandeiras de unidade entre os povos do mundo, recebendo o nome de Assembleia Internacional dos Povos.

Dentre algumas ações concretas realizadas nesses espaços políticos organizativos são referências as brigadas internacionalistas compostas por militantes Sem Terra e também de outras organizações populares que se dispõem por um determinado período de anos contribuir em comunidades camponesas de um país eleito, cujo principal critério é realizar ações de solidariedade. Por exemplo, já houve experiências desse tipo na Nicarágua, Haiti, Moçambique, Venezuela, Cuba entre outros. As brigadas organizam atividades em torno da produção agroecológica, saúde, gênero e diversidade, juventude, formação política e processos de alfabetização de jovens e adultos como é o caso da brigada que está na Zâmbia. Sabemos que há muitas lições e aprendizados para cada experiência desenvolvida, o que requer uma elaboração específica.

Ressaltamos ainda a participação em campanhas globais de denúncia e solidariedade com povos; relações políticas e diálogos com representações diplomáticas de outros países em território nacional, bem como a realização de intercâmbios temáticos, reuniões e relações bilaterais entre organizações populares. Além disso, do ponto de vista da escolarização acontecem cursos em parcerias com Instituições de Ensino Superior para pós graduações que abrangem outros países, como por exemplo o Programa de Desenvolvimento Territorial da América Latina e Caribe da Universidade Estadual Paulista "Júlio de Mesquita” (UNESP).

Esse leque de ações possui uma centralidade dentro da estrutura organizativa do MST a partir do Coletivo de Relações Internacionais (CRI), envolvendo militantes em níveis regionais, estaduais e nacionais dos territórios nos quais o MST se organiza. O trabalho desse coletivo que considera as diferentes modalidades e as dimensões na concepção do internacionalismo são permeadas por linhas políticas que impulsionam a atuação dos militantes envolvidos, cuja síntese parte da afirmação de que a solidariedade internacional não é distribuir o que nos sobra, mas

compartilhar o que nos fará falta. O que, por sua vez, implica na construção conjunta com outros povos, no respeito às dinâmicas políticas das organizações, respeitando a cultura e história do povo do território de cada país, potencializar a autonomia e estabelecer relações entre organizações como sujeitos coletivos. 
Debate

Evidentemente, o internacionalismo no MST vai além das atividades e processos organizados desde o CRI, uma vez que há uma prática formativa para que a concepção do Movimento permeie toda a sua militância. Este é um ponto crucial para o MST pois não reduz o internacionalismo às oportunidades de viagens internacionais. Muito pelo contrário, a necessidade e o esforço permanente de internalizar o internacionalismo no MST implica em envolver a base dos territórios em nosso país.

Nesse sentido, o internacionalismo é também o que se faz para dentro do Movimento que se materializa nos territórios através de processos de formação e informação, de ações culturais, mobilizações de solidariedade e toda uma simbologia construída de resgate e valorização de processos históricos importantes, de memória aos lutadores e lutadoras de outros povos do mundo, exemplos de prática de compromisso e solidariedade.

\section{A formação internacionalista e a prática política e pedagógica na ENFF}

A ENFF é um dos territórios no qual o MST materializa a sua concepção de internacionalismo. Nesse sentido, a concepção de formação que enraíza no fazer cotidiano da Escola, assim como do conjunto do Movimento, é sobretudo um processo para além da sala de aula, de cursos e seminários. Esse processo possui algumas características essenciais, sendo que a primeira é a compreensão de um processo amplo, no sentido que deve envolver a totalidade dos sujeitos da organização. Isso ilustra o componente de movimento de massas que caracteriza a natureza do próprio MST. Diante disso, a formação política não é direcionada apenas para uma elite dirigente, a sua amplitude deve envolver todos os sujeitos, a partir de suas realidades, particularidades e universalidades.

A segunda característica é que a formação política é um processo contínuo, ou seja, envolve um conjunto de ações que acontecem ao longo do tempo na mesma medida em que são conectadas entre si, em sua intencionalidade para qualificar a luta pela terra, pela reforma agrária e pela mudança estrutural da sociedade. Essa característica busca sobretudo imprimir aos processos formativos a relação entre ações de natureza teórica e prática, ao mesmo tempo que conecta o estudo, a análise, a construção de conhecimento às diversas práticas que se desenvolvem nos territórios.

A terceira característica é de que a formação é um processo sistemático no sentido de que cada um de seus componentes ou cada atividade desenvolvida deve ser sistematizada num exercício de síntese para ir acumulando as lições, aprendizados, limites, contradições e avanços. Para tanto esse acúmulo pode ser no âmbito de conteúdos e de reflexões de natureza metodológica e pedagógica. O importante é que esse acúmulo sistematizado contribua para a construção de novas atividades, novas abordagens, retificações ou ajustes futuros. Além disso, a sistematização deve ser essencialmente coletiva. Não se trata de sistematizar ou medir acúmulos de natureza individual, mas ter uma síntese de uma coletividade para outra. 
Debate

Vejamos que esses elementos são primordiais para alimentar a concepção de formação do Movimento, sem que seja necessário “começar do zero" em algumas das ações. Nesse sentido, visibiliza a construção do conhecimento coletivo que é sempre maior que a soma das partes individuais, mas envolve todos os sujeitos do processo formativo como os educandos, educadores, coordenação político pedagógica, instâncias políticas entre outros.

A concepção de formação do Movimento impacta não apenas na organização, planejamento, execução e avaliação dos processos realizados na ENFF, mas sobretudo incidem na prática pedagógica que se realiza na Escola, pois esta se configura como mais um espaço nos quais a formação política se realiza no MST. Reafirmamos que essa concepção de formação se associa a um projeto político de sociedade, desde uma visão de mundo e com objetivos políticos estabelecidos, sendo assim a formação política não é a estratégia do Movimento, mas responde às questões colocadas por esta, pois sem militantes, dirigentes e quadros com capacidade política não avançaremos na conquista por uma outra sociedade.

Embora a concepção de formação do MST seja o pressuposto para a construção da ENFF e a determinante de seus próprios objetivos gerais, a prática pedagógica da Escola busca adequar a forma na qual essa concepção se materializa no seu fazer pedagógico cotidiano passando por dois componentes metodológicos que são as dimensões formativas e os tempos educativos.

As dimensões pedagógicas atravessam os sujeitos que participam das atividades formativas respeitando alguns critérios e um deles que os participantes são indicados por coletivos, sejam movimentos populares, partidos políticos do campo popular, sindicatos ou outras formas de organização. Todos estão na condição de sujeitos coletivos, ou seja, como representação de suas respectivas organizações. Assim, participar de um processo formativo na ENFF não parte de vontades ou iniciativas individuais, mas depende das estratégias das organizações populares e o papel que a formação política assume dentro de cada uma delas.

Entretanto, esses sujeitos coletivos são, em si mesmo, muito diversos no que trata de suas realidades, trajetórias, habilidades e características. O sujeito coletivo se dá no âmbito mais amplo da política e de objetivos estratégicos determinados, mas no plano individual, suas formas de aprender e apreender os processos formativos possuem singularidades. Em diálogo com isso, as dimensões formativas buscam gerar espaços diversificados com ênfases específicas que contribuam para uma experiência dialética entre essas singularidades e a busca por um processo coletivo.

As principais dimensões formativas elaboradas no Projeto Político Pedagógico (PPP) da Escola são: o estudo que exige um programa com temas elaborados de acordo com a intencionalidade desejada, que conta com a colaboração voluntária de educadores, que promove o diálogo, reflexões e sínteses individuais e coletivas, pois:

Assumimos o método marxiano de construção do conhecimento, a pressupor a captação empírica e sincrética da realidade como ponto de partida, as mediações abstratas do pensamento como possibilidade para a superação dessa condição, tendo em vista a apreensão concreta da realidade como síntese de múltiplas 
determinações ou como "rica totalidade das determinações e de relações numerosas” (ENFF, 2020, p.31-32).

A dimensão do trabalho na perspectiva de um princípio como nos ensina a Pedagogia Socialista contrariando às características que o trabalho adquiriu no modo de produção capitalista. Vejamos:

\begin{abstract}
A própria ENFF, fruto do trabalho voluntário, obra coletiva em construção permanente, é a materialização de uma perspectiva do trabalho diferente da sociedade capitalista. Assim, é compromisso de todas (os) que passam pela Escola contribuir com sua construção, dispondo de tempo e força de trabalho. Forja-se uma nova geração de militantes, dirigentes e quadros, que estudam e participam dos processos de organização, dispostos a realizar todos os tipos de tarefas necessárias na luta da classe trabalhadora (idem, 2020, p. 34).
\end{abstract}

Outro elemento como dimensão formativa é a organicidade como o jeito de organizar o funcionamento de um espaço físico e político, definindo as suas funções e respectivos responsáveis. Além disso, é um jeito dinâmico de fazer acontecer, não é estático e por isso passivo de mudanças de acordo com o que a realidade demandar, conforme expressa:

A organicidade é o elemento que permite antecipar o que queremos construir coletivamente, ou seja, por meio dela é possível colocar em prática embriões da sociedade socialista, desde as práticas de cooperação, produção agroecológicas e novas relações humanas com igualdade e equidade de gênero. Portanto, a organicidade, intenciona à participação de todas e todos no processo, de forma ativa, protagônica, responsável e consciente, possibilitando a elevação de forma permanente do nível de consciência e de conhecimento de todos (as) sujeitos (as) envolvidos (as) (ibidem, 2020, p. 35).

As demais dimensões são a da mistica que impulsiona permanentemente a esperança e o acreditar em construir um projeto novo de sociedade, contendo elementos da dimensão da cultura que apresenta o contraponto ao projeto capitalista de cultura de massas, bem como a relação com a dimensão dos valores humanistas e socialistas que coloca em perspectiva o ser humano como constituinte de valores capitalistas que precisam ser desconstruídos e construir novos valores como o da solidariedade, do companheirismo, do respeito, do internacionalismo entre outros.

Diante disso, os processos formativos devem levar em conta as dimensões formativas no momento de construir os programas e metodologias, porém não se tratam de conteúdos temáticos, mas de abordagens que exigem metodologias específicas. A elaboração de diferentes metodologias é necessária para que contemplem efetivamente nos tempos pedagógicos.

Os tempos pedagógicos são os momentos específicos dentro de uma programação nos quais uma ou outra das dimensões pedagógicas é enfatizada, de modo que uma mesma dimensão, por exemplo, a dimensão do estudo pode resultar em diferentes tempos pedagógicos como aulas, seminários, leituras e mesas de debate. Outro exemplo é a dimensão da organicidade, que parte do pressuposto de que o aprendizado e ensino passam pelo protagonismo dos participantes nas decisões relativas a um curso e assim, desenvolvem o exercício prático da responsabilidade coletiva e construção de consenso pode resultar em tempos pedagógicos como reuniões de Núcleos de Base 
de uma turma, Coordenação Geral do Curso, coordenação de um dia das atividades, comissões específicas, etc.

Dessa maneira, os tempos pedagógicos podem ser compreendidos como a concretização, a prática pedagógica de diferentes dimensões que perpassam o ensino e aprendizado em sua totalidade. É o que possibilita que as dimensões pedagógicas sejam mais que enunciados e se concretizem em determinado processo formativo contribuindo para seu planejamento.

Cabe enfatizar que as dimensões pedagógicas e os tempos pedagógicos compõem uma totalidade, tal qual o processo formativo em si. Sua divisão em distintas nomenclaturas serve mais para anunciar uma ênfase particular do que definir como uma dimensão isolada das demais. Alguns exemplos nos ajudam a compreender essa afirmação. Se em um determinado curso a dimensão do trabalho se materializa nos tempos pedagógicos trabalho militante, trabalho necessário ou doméstico e trabalho voluntário, na medida em que os educandos se auto organizam em grupos para fazer o planejamento e a execução dessas tarefas, além da dimensão do trabalho, a dimensão da organicidade também se materializa. Ou quando da dimensão da cultura aparece como noite cultural, a dimensão do estudo aparece na pesquisa que os educandos fazem para criar uma apresentação desde suas culturas particulares, seja através da música, da poesia, das artes plásticas, etc.

Embora haja muitos exemplos possíveis para demonstrar a prática vivenciada, o importante é que ao articular por um lado uma concepção de formação, e por outro diferentes dimensões formativas afirmamos que formação não é só curso, que curso não é só aula e que aula não é só exposição de conteúdo. Assim, os processos formativos realizados na ENFF consistem em processos de convivência e de construção coletivas por meio de uma multiplicidade de tempos pedagógicos que, articulados, expressam dimensões essenciais dos processos de ensino aprendizagem que considerem o perfil dos educandos, a natureza de suas organizações populares e dos objetivos específicos desse processo diante de uma concepção mais ampla da formação política.

Enfatizamos que às exigências metodológicas que essa abordagem implica se somam exigências de natureza político pedagógicas, uma vez que esses processos não são espontâneos e estão atrelados a determinadas intencionalidades definidas pelo caráter político das estratégias de formação, pois todo o conhecimento compartilhado e construído coletivamente deve contribuir para a organização da classe trabalhadora na defesa de seus interesses e suas conquistas objetivas, articulando-as na totalidade.

Nesse sentido, o internacionalismo se apresenta como um componente essencial dos processos formativos na ENFF com a intencionalidade de consolidar uma identidade de classe que, ao ressaltar e afirmar a diversidade dos sujeitos, dialeticamente explicita o que há de universal em seus interesses, de tal modo que a unidade em lutas políticas aparentemente distintas é, em essência, a forma coletiva de sua realização.

A ENFF tem a sua abrangência internacional evidenciando que o internacionalismo está presente em seu conjunto de atividades às vezes de forma mais explícita, em outras de maneira 
Debate implícita nas suas abordagens político pedagógicas, pois a intencionalidade dos processos formativos da Escola implica articular as especificidades na diversidade dos sujeitos envolvidos em aspectos comuns de classe. Nos marcos dessa diversidade, os militantes de organizações de diversos países e continentes do mundo fazem parte das atividades que imprime uma qualidade ao exercício prático do internacionalismo.

Podemos destacar alguns aspectos de como o internacionalismo acontece na Escola, um deles são os conteúdos trabalhados nos vários processos formativos, sobretudo a abordagem dos conteúdos. Por exemplo, a forma de abordar a bistória do Brasil prescinde de uma compreensão do estabelecimento do sistema capitalista com seus polos centrais na Europa e as suas periferias dependentes. Outro exemplo é ao tratar de questão agrária no Brasil, a abordagem temática passa por identificar as particularidades do desenvolvimento do capitalismo na agricultura em relação a outras formas historicamente estabelecidas em outras partes do mundo. Ou ainda, nos conteúdos relacionados ao tema teoria da organização é sempre ressaltado um conjunto de experiências históricas que contribuíram para acúmulos gerais da classe trabalhadora muito além de fronteiras nacionais. Ou seja, uma abordagem internacional independe dos temas em si, mas da necessidade de abordar a compreensão da realidade a partir da articulação de padrões de desenvolvimento internos e externos, dialeticamente.

Outro aspecto desse exercício prático de internacionalismo reside na presença constante de educandos nos processos formativos provenientes de diversas partes do mundo, não apenas no interior de uma turma em um processo formativo internacional, sobretudo no conjunto de dinâmicas de intercâmbios que se estabelecem na interação entre as diversas turmas e a totalidade dos sujeitos que se fazem presentes na ENFF em um determinado período. A realização simultânea de processos formativos nacionais, regionais e internacionais é uma das formas de intencionalizar essa convivência que resulta em trocas de toda ordem.

Ressaltamos que esses intercâmbios se ampliam através dos tempos pedagógicos que são planejados, conduzidos e avaliados conjuntamente. Pode-se dizer que os períodos em sala de aula são os espaços mais particulares das turmas. As demais dimensões e tempos pedagógicos delas decorrentes exigem um nível de integração, convivência e intercâmbio entre todos os presentes na Escola em determinado momento. Essa convivência fora da sala de aula, por ser baseada no protagonismo dos educandos para a construção das atividades, resulta em um exercício pleno de internacionalismo. É um exercício de reconhecer no outro formas distintas de ver o mundo, de trabalhar, de fazer política, de tomar decisões, de construir consensos, de comunicar-se, de relacionarse, etc.

Além dos aspectos anteriores, apresentamos mais um que é o processo de sistematização, da síntese, dos acúmulos gerados tanto pelos conteúdos abordados como pela convivência coletiva na diversidade internacional em um contexto de protagonismo dos participantes. O papel da intencionalidade político pedagógica e da reafirmação dos objetivos da Escola são essenciais para 
Debate garantir que os acúmulos gerados não sejam meras somatórias das particularidades envolvidas, mas uma afirmação dos elementos comuns que repercutem na identidade de classe dos sujeitos e na construção de um projeto de superação da ordem hegemônica.

Nesse sentido, no aspecto dos conteúdos e temas, será possível refletir e compreender uma história para além da história oficial e factual de cada país, mas num processo contínuo de forças econômicas, políticas, sociais, culturais estruturantes e as suas derivações particulares em contextos específicos que permite identificar componentes comuns em estratégias e formas de luta das distintas, bem como, refletir sobre as suas abrangências e o acúmulo para as experiências organizativas.

Trata-se de consolidar coletivamente as bases que orientem questões comuns que contribuam com a prática cotidiana dos militantes, dirigentes e quadros em seus territórios e nas suas organizações populares. Dessa maneira, reafirmamos a compreensão de que cada realidade e seus sujeitos possuem exigências próprias para a construção de alternativas que alimentem um projeto estratégico e internacional, ou seja, da classe trabalhadora, seguindo a orientação do Manifesto do Partido Comunista de 1848, "Proletários de todo o mundo, uni-vos" (ENGELS \& MARX, 2008, p. 21).

Para enfatizar todas as reflexões abordadas anteriormente, queremos trazer algumas características históricas que têm reafirmado permanentemente o significada da ENFF para o MST, mas especialmente para a classe trabalhadora mundial. Vejamos que alguns dirigentes do Movimento estudaram em processos de formação política em outras organizações e em outros países, conforme nos explica um dos dirigentes do Movimento, Edgar Kolling:

La experiencia que um buen número de compañeros y compañeras del MST tuvimos em Cuba fue muy importante. Yo hice um curso allá em la escuela del partido, 400 estudiantes de 44 países y um centenar de organizaciones. El intercambio de ideas, las conversaciones de las organizaciones de Perú, Colombia, Argentina, Chile, Bolívia, Venezuela, México, ha supuesto uma gran riqueza para nosostros. Uma experiencia personal pero también es uma experiencia que cada uno lleva a su organización (BAIDES, 2020, p. 146).

Da decisão política do MST pela construção de um espaço físico para fortalecer as atividades de formação que já desenvolvia no interior do país, o Movimento contou com um amplo apoio e solidariedade nacional e internacional, com brigadas de militantes Sem Terra e de outras organizações populares, bem como de amigos internacionalistas para levantar paredes e produzir o que Ademar Bogo denominou de "a escola de terra com cimento é um simbólico monumento. Representa a origem e a continuidade. Quem viver verá e vencerá” (ENFF, 2020, p. 14).

As palavras de Bogo ecoaram no Seminário Internacional A formação de quadros políticos: elaboração teórica, experiências e atualidade, que marcou na história a inauguração da construção da ENFF, em janeiro de 2005. Nas palavras de Adelar Pizetta, dirigente e formador:

Otros países de América Latina desarrollaban 1 formación de cuadros y nosostros lo fuimos incorporando. En la inauguración de la ENFF em 2005, organizamos um gran seminário internacional de formación, para escuchar otras experiencias de formación de cuadros para ir construyendo la ENFF. Lo que teníamos claro 
Debate

es que no podíamos transplantar para la Florestan Fernandes, un esquema, uma receta. El desafio era conocer experiencias, conocer las demandas del MST y construir algo inovador (idem, 2020, p. 147).

Da inauguração em 2005 até hoje somam-se 16 anos de história recheada de muitos aprendizados, desafios e contradições que ampliam os desafios políticos e pedagógicos da Escola. Porém, fomos desenvolvendo práticas que são referenciais para as organizações populares. Queremos apresentar de forma breve a experiência com o bosque da solidariedade, no qual as turmas, educadores, artistas, personalidades do campo político nacionais e internacionais ao marcar presença em alguma atividade deixam uma árvore plantada, podendo ser frutíferas, ornamentais ou nativas, como simbologia de unidade e de reverencia ao cuidado com a natureza. Nos registros da ENFF constam 98 (noventa e oito) espécies de árvores plantadas por pessoas como Daniel Vigllietti, Benício del Toro, Letícia Sabatela, Vânia Bambirra, entre outros.

Além disso, as turmas de cursos nacionais ou internacionais têm a prática de construir a identidade da turma elegendo um nome de uma lutadora, de um lutador ou de um processo de luta ocorrido em algum território, por exemplo nomes como Violeta Parra, Peloton Mariana Grajales, Marielle Franco, Begoña Garcia, Ernesto Che Guevara, etc. Para essa definição, os educandos organizam pesquisas, debates e místicas que apresentem o legado que querem homenagear como turma.

Ressaltamos a dimensão cultural que a ENFF aglutina com pessoas de vários lugares, onde o idioma é um desafio possível de superação de quem fala inglês, francês, italiano, espanhol, português e os dialetos regionais especialmente no continente africano. A expressão está no olhar, no sorriso, na mística, nas danças, nas bebidas e comidas típicas que cada país ou região pode apresentar em um determinado momento para a coletividade. Esse jeito de vivenciar as experiências dos outros oportuniza maior integração, construção de novos valores e conhecimento das raízes culturais dos sujeitos participantes.

Para melhor compreensão sobre quem são os sujeitos presentes na Escola, apresentamos como a mesma organiza os cursos de formação no seu calendário anual considerando quatro núcleos que são o núcleo de Teoria Política Nacional que como o próprio nome diz são para as organizações populares do campo e da cidade brasileiros; o núcleo Formal que está vinculado ao processo de escolarização em parcerias com Instituições de Ensino Superior; núcleo Urbano Popular que são articulados junto às organizações sindicais e políticas; e o núcleo de Teoria Política Internacional que articula com as organizações latinas americanas e demais continentes a presença de militantes nos cursos organizados. No calendário anual existem cursos para a América Latina que são Formação de Formadores e Teoria Política Latino Americana; Teoria Política em idioma inglês e francês; Método e Metodologia Internacional; Geopolítica e Internacionalismo, além de seminários temáticos.

A partir dessas experiências podemos afirmar que já passaram pela ENFF centenas de organizações populares, dezenas de países representados e milhares de militantes, dirigentes e quadros, homens, mulheres, jovens, LGBTQI+, bem como dezenas de crianças que ocupam a 
Debate

Ciranda Infantil Saci Pererê, incluindo crianças de outros territórios além do Brasil. Todo esse movimento de articulações desencadeou a construção física e pedagógica de outras escolas que têm na Florestan Fernandes uma referência.

No cotidiano da ENFF ao longo de sua história, contamos com o trabalho da Brigada Apolônio de Carvalho (BAC) composta por militantes, dirigentes e quadros do MST de vários Estados, bem como com representantes de outras organizações populares como Movimento dos Pequenos Agricultores (MPA), Movimento pela Soberania Popular na Mineração (MAM), Movimento dos Trabalhadores por Direitos (MTD) entre outros. Alguns membros da BAC também foram contribuições de outros países como Argentina, País Vasco e outros. A brigada recebe o nome do saudoso militante comunista e internacionalista Apolônio de Carvalho cuja palavra de ordem é "Apolônio de Carvalho internacionalista, na formação de quadros pra luta socialista", reafirmando cotidianamente o entusiasmo de formar a classe trabalhadora. Que essa palavra de ordem possa seguir ecoando no interior da ENFF e ressoe na libertação do povo oprimido em qualquer parte do mundo.

\section{Conclusão}

A título de conclusão podemos dizer que os elementos apresentados neste breve texto são insuficientes para compreender a totalidade que a ENFF representa no seu fazer político pedagógico cotidiano e como este debate incide na materialidade de seus processos formativos internacionais.

Dessa maneira, a ENFF contribui para aprofundar a concepção de internacionalismo do MST no sentido de ir além da diversidade de nacionalidades dos participantes e egressos dos processos formativos, bem como reafirmar uma perspectiva de classe. Nessa direção, é um processo que envolve o internacionalismo como um elemento fundante do MST e da ENFF; que busca construir uma identidade comum, de classe, desde a prática e convivência coletiva, e não apenas em discursos e teorias, além de contribuir para forjar uma unidade que alimente formas de luta para a superação da ordem burguesa.

Podemos afirmar que a ENFF, ao construir internacionalismo, constrói a si mesma como projeto político pedagógico da classe trabalhadora. Evidente que no conjunto de processos, abordagens e dinâmicas tratadas não são isentas de contradições, essas das mais variadas ordens. Porém, parte-se da constatação que a própria realidade assim o é, pois são nas dinâmicas resultantes de tudo o que acontece ao longo de um processo formativo que residem os potenciais para novos aprendizados e ajustes feitos, sobretudo, com o protagonismo dos participantes.

Para finalizar, salientamos que a ENFF como um todo, seu internacionalismo e cada um de seus processos formativos avançam na medida em que avança a luta de classes. Ao se constituir como uma escola da e para a classe trabalhadora dialeticamente contribui e responde aos processos políticos mais profundos do contexto de superação da ordem do capital. Essa postura diante dos mais amplos e específicos contextos, mais favoráveis e desfavoráveis correlações de força, não é 
Debate apenas uma postura de natureza pedagógica, mas uma postura política que dimensiona constantemente o seu papel e a natureza de sua contribuição para processos mais profundos de transformação social. Quanto mais as contradições da classe trabalhadora, em especial aquelas que ajudam avançar na unidade na diversidade, forem componentes das dinâmicas da ENFF, mais a Escola reafirma sua posição de classe internacionalista.

\section{Referências:}

BAIDES, B. C. Pedagogías Políticas para Disputar Territorios: La Experiencia Educativa del MST. España: Fundación Betiko, 2020.

ENFF. A Política de Formação de Quadros. São Paulo: Editora Expressão Popular, 2020.

ENFF. Projeto Político Pedagógico. São Paulo: Editora Expressão Popular, 2020.

ENFF. ENFF: Uma Escola em Construção (1996-2020). São Paulo: Editora Expressão Popular, 2020.

ENGELS, F. MARX, K. Manifesto do Partido Comunista. São Paulo: Editora Expressão Popular, 2008.

ITERRA. A gente Cultiva a terra e ela cultiva a gente: História do MST. Veranóplis, 2015.

MST. Linhas Políticas para nossas ações internacionalistas. São Paulo, 2015.

\section{Notas:}

1 Especialista em Estudos Latino Americanos, ORCID: https://orcid.org/0000-0002-9234-3830 Lattes: http://lattes.cnpq.br/9472068537066117 email: fabiotomaz@gmail.com

${ }^{2}$ Doutoranda em Educação. UNICAMP, ORCID: https://orcid.org/0000-0003-4277-5974, Lattes: http://lattes.cnpq.br/0760708226111214. email: rosanacfernandes40@gmail.com,

Recebido em: 28 nov 2021

Aprovado em: 15. dez.2021 